\title{
Üçüncü Basamak Bir Hastanede 4 Yıllık Sezaryen Doğumlarının Oranları ve Endikasyonları
}

\section{Rates and Indications of Cesarean Deliveries during a 4-Year Period in a Tertiary Hospital}

\author{
Kıymet YEŞİLÇİÇEK ÇALIK ${ }^{\mathrm{a}}$, Reyhan ERKAYA ${ }^{\mathrm{b}}$, Özlem KARABULUTLU ${ }^{\mathrm{c}}$
}

ÖZ Amaç: Bu çalışmada amaç 2013-2016 yılları arasında sezaryen oranlarını ve yıllara göre sezaryen endikasyonlarının dağılımını incelemektir. Gereç ve yöntem: Çalı̧̧ma, 2013-2016 tarihleri arasında TC Sağlık Bakanlığı Trabzon Kanuni Eğitim ve Araştırma Hastanesi Kadın Hastalıkları ve Doğum Kliniği'nde gerçekleșen 12.315 doğumun kayıtları retrospektif olarak incelenerek gerçekleştirildi. Bu doğumların tarihi, şekli, gebenin yaşı ve sezaryen endikasyonu hasta dosyalarından faydalanılarak kaydedildi. Verilerin analizinde tanımlayıcı istatistiksel metotlar (Frekans, Yüzde, Ortalama, Standart sapma) ve Pearson Ki-Kare testi ve Fisher Exact test kullanıldı. İstatistiksel anlamlılık için $\mathrm{p}<0 ; 0.05$ değeri kabul edildi. Bulgular: 4 yıllık süreçte toplam doğum sayısı 12.315 idi ve bunların 5558'ine (\%45.1) sezaryen yapıldı. Geçirilmiş uterin cerrahi (\%58.2), baş pelvis uyumsuzluğu (\%16.1), fetal sikint1 (\%12.8), makat prezentasyonu (\%3.7), iri bebek (\%2.0) idi. 2013-2016 y1llar1 arasinda gerçekleşen vagiinal ve sezaryen doğumlar sonrasında morbidite ve mortalite vakası yaşanmadı. Yıllara göre sezaryen ve vajinal doğum oranları arasında istatistiki bir fark bulunmadı $(\mathrm{p}=0.291)$. Sonuç ve Öneriler: Çalışma sonucunda sezaryen oranı (\%45.1) Türkiye ortalamasın altında (\%53) fakat Dünya Sağlı Örgütü’nün belirlediği orandan (\%15) oldukça yüksektir. Çalışmada tüm yıllar için en sık endikasyon geçirilmiş uterin cerrahi olup yıllara göre sezaryen endikasyon oranlarında anlamlı değişiklik izlenmedi. Sezaryen oranlarının düşürülmesi için kadınların normal doğumumun yararları konusunda eğitilmesi, normal doğum sırasında ağrı kontrolü için desteklenmesi, kliniklerin fiziki koşullarının iyileştirilmesi, ilk gebeliği olan hastalara sezaryen kararı verilirken endikasyonların iyi değerlendirilmesi, medikal endikasyon olmadan anne isteğine bağlı yapılan operasyonların önlenmesi, ebe, hemşire ve doğum hekimlerinin düzenli olarak eğitimi önemlidir.

Anahtar Kelimeler: Endikasyon, sezaryen doğum, sezaryen endikasyonları, sezaryen oranları

ABSTRACT Objective: The aim of this study is to examine the cesarean rates between 2013 and 2016 and the distribution of cesarean indications over the years. Materials and methods: The study was performed retrospectively by examining the records of 12,315 births performed at Obstetrics and Gynecology Clinic at TR Ministry of Health Public Hospitals Trabzon Kanuni Training and Research Hospital between 2013 and 2016. The history, type and cesarean indications of these births and the ages of the pregnant women were recorded using patient files. To analyze the data, descriptive statistical methods (Frequency, Percentage, Mean, and Standard deviation), Pearson Chi-Square test and Fisher Exact test were used. For statistical significance, $p<0.05$ was accepted. Findings: The total number of deliveries during the 4-year period was 12.315 and 5558 of them (45.1\%) were cesarean sections. The main indications of caesarean sections were; 3195 previous uterine surgery $(58.2 \%)$, 899 head-pelvis mismatches $(16.1 \%), 715$ fetal distress (12.8\%), 210 breech birth (3.7\%) and 114 large babies (2.0\%). There were no morbidity and mortality cases after vajinal and cesarean deliveries between 2013 and 2016. There was no statistically significant difference between cesarean and vajinal birth rates according to the years $(\mathrm{p}=0.291)$. Conclusion and Recommendations: The study demonstrated that the cesarean rate $(45.1 \%)$ as below the average of Turkey $(53 \%)$, but it was much higher than the one determined by the World Health Organization (15\%). The most frequent indication in the study for all years was previous uterine surgery and there was no significant change in cesarean section rates over the years. There are some methods that can be applied to decrease the cesarean rate such as to control primary cesarean rates, it is also important to educate women about the benefits of normal birth and to support and encourage them for pain control during birth, improve the physical conditions of the clinic, the prevention of the operations which are applied only for maternal

Geliş Tarihi /Received: 30-03-2018 Kabul Tarihi/Accepted:14-04-2018

${ }^{a}$ Yrd. Doç. Dr. Karadeniz Teknik Üniversitesi Sağlık Bilimleri Fakültesi Hemşirelik Bölümü, Trabzon, Türkiye, e-mail: omrumyesilcicek@hotmail.com, special email: kyesilcicek@ktu.edu.tr, ORCID ID: 0000-0001-7146-3385

bÖğr. Gör. Karadeniz Teknik Üniversitesi Sağlik Bilimleri Fakültesi Hemşirelik Bölümü, Trabzon, Türkiye, e-mail: reyhanozturk30@hotmail.com, ORCID ID: 0000-0002-9061-2742

'Yrd. Doç. Dr. Kafkas Üniversitesi Sağlık Bilimleri Fakültesi Ebelik Bölümü, Kars, Türkiye, e-mail: okarabulutlu@ gmail.com, special email: okarabulutlu@ atauni.edu.tr, ORCID ID:0000-0001-7477-3450

Araştırma 22-24 Mart 2018 tarihleri arasında gerçekleştirilen I.Uluslararası ve II. Ulusal Kadın Sağlığı Hemşireliği Kongresi’nde Poster Bildiri olarak sunulmuştur.

Sorumlu Yazar/Corresponding Author: Kıymet Yeşilçiçek Çalık,e-mail: kyesilcicek@ktu.edu.tr 
request without any medical indications, a good evaluation of indications when a decision is made for cesarean section if it is the first pregnancy and educate midwives, nurses, and obstetricians regularly.

Key Words: Cesarean indications, cesarean, cesarean section rates

\section{Giriş}

Sezaryen dünyada en sik yapılan cerrahi girișimlerden biridir ve genel olarak, vajinal doğumda anne ve/veya bebek için artan morbidite ve mortalite riski olduğu veya vajinal doğum eyleminin güvenle tamamlanamayacağı durumlarda abdominal insizyon ile fetusun doğumu olarak tanımlanmaktadır (1-4).

Dünya Sağl1k Örgütü (DSÖ), 1985’ten beri ideal sezaryen oranın $1 \% 10$ - 15 olarak belirtmiş olsa da bu oran gelişmiş ve gelişmekte olan ülkelerde hızla artmaktadır. DSÖ 2015 verilerine göre Türkiye dünya da en yüksek sezaryen oranlarına sahip ilk beş ülkenin (Dominion Cumhuriyeti \%56.4, Brezilya \%55.6, Misır \%51.8, Türkiye \%50.4, İran \%48, Çin \%47) dördüncüsü ve OECD ülkeleri arasinda ise birinci sirada yer almaktadır (5). Türkiye'deki sezaryen oranlarının yıllara göre ciddi bir artış eğiliminde olduğu, 1993 yılından 2015'e kadar \%7'den \% 53'e yükseldiği bilinmektedir (6,7). Yine Sağlık Bakanlığı 2015 verilerine göre sezaryen doğumların \%37.5'inin Sağlık Bakanlığı, \%69.3'ünün üniversite hastanelerinde, \%70.5'inin ise özel hastanelerde yapılmaktadir (7).

Günümüzde sezaryen ameliyatları en s1k mükerrer sezaryen, distosi, fetal distres ve anormal fetal prezentasyon gibi dört ana nedenle uygulanmaktadır $(2,3,7)$. Diğer endikasyonlar ise ilk doğumların ileri yaşlarda yapılması, doğum indüksiyonunu artması, yardımcı üreme tekniklerinin kullanımındaki artış ve bu artışa bağlı çoğul gebelik oranlarının yükselmesi, obezite prevalansının artması, elektronik fetal monitör kullanımının yaygınlaşması, makat prezentasyonlu vakaların sezaryen ile doğurtulması, forseps ve vakumun daha az kullanılması, preeklamptik gebelerde doğum indüksiyonunun azalması, sezaryen doğum sonras1 vajinal doğumun tercih edilmemesi, vajinal doğum ile ilişkili pelvik taban hasarının artması, sezaryen doğumun bebek için daha güvenli olduğuna dair yanılgı, hem anne hem de sağlık profesyonelleri için daha uygun bir yöntem olmas1s1 düşüncesi, normal doğum korkusu nedeniyle anne isteğinin artması gibi sosyal endikasyonlar yanında vajinal doğum ve operatif doğum ile ilgili medikolegal problemlerin hekimler üzerinde oluşturduğu bask1 şeklinde sıralanabilir (2-4,8-10). Tibben gerekli olduğunda, sezaryenin perinatal mortalite ve morbiditeyi etkili olarak önlediği ancak endikasyonun olmadiğ durumlarda anne veya yenidoğan mortalitesini azalttığına dair kanıt olmadığı bildirilmektedir. Nitekim yapılan araştırmalarda \%15'in üzerindeki sezaryen oran-ları, anne ve yenidoğan mortalite hızlarındaki azalmayla ilişkili bulunmamıştır (5,11-13).

Sağlık Bakanlığ 1 tarafindan anne sağlığını korumak amacıyla ülke genelinde kamu ve özel sağl1k kuruluşlarında doğum eylemi ve sonuçlarının izlenmesi çalışmaları yapılmaktadır. $\mathrm{Bu}$ çerçevede sezaryen endikasyonları ve sonuçlarının izlenmesi de önem arzetmektedir. Bu nedenle bu çalışma 2013-2016 yılları arasında sezaryen oranlarını ve yıllara göre sezaryen endikasyonlarının dağılımını incelemek için yapılmıştır.

\section{Gereç ve Yöntem}

Çalışma, 01.01.2013-31.12.2016 tarihleri arasında TC Sağlık Bakanlığı Türkiye Kamu Hastaneleri Kurumu Trabzon Kanuni Eğitim ve Araştırma Hastanesi Kadın Hastalıkları ve Doğum Kliniği'nde gerçekleşen 12.315 doğumun kayıtları retrospektif olarak incelenerek gerçekleştirildi. $\mathrm{Bu}$ doğumların tarihi, şekli, gebenin yaşı ve sezaryen endikasyonu hasta dosyalarından faydalanılarak kaydedildi. Araştırma öncesi ilgili kurumdan yazılı izin ve etik onay alındı ve çalışmada hastaların kişisel bilgilerinin gizliliğine önem verildi. Verilerin analizinde tanımlayıcı istatistiksel metotlar (Frekans, Yüzde, Ortalama, Standart sapma) ve niteliksel verilerin karşılaştırılmasında Pearson Ki-Kare testi ve Fisher Exact test kullanıldı. İstatistiksel anlamlılık için $\mathrm{p}<0.05$ değeri kabul edildi.

\section{Bulgular}

Yapılan arşiv taraması sonucunda 2013-2016 yılları arasında Trabzon Kanuni Eğitim ve Araştırma hastanesinde toplam 12.315 doğum gerçekleştiği saptanmıştır. Bunların 5558'i 
sezaryen ile doğumdur. Tüm sezaryen vakaları içinde primer sezaryen oranı $\% 18.8$, geçirilmiş uterin cerrahi oranı \%26.2 ve dört yılın sezaryen oran1 \%45.1'dir (Tablo 1). Y1llara göre sezaryen dağglımı incelendiğinde; 2013'te 1232 (\%45.8), 2014 'te 1360 (\%43.7), 2015'te 1514 (\%45.3), 2016'da 1452 (\%45.7) kadına sezaryen uygulandığ1 ve dört yıllık süreçte sezaryen oranlarının değişmediği görülmektedir (Tablo 1) (Şekil 1). Tüm sezaryen vakaları içinde 35 yaş altı kadınlarda sezaryen oranı \%66,8 35 yaş ve üstü kadınlarda ise \%33,2 olarak saptandı (Tablo 1).

Tablo 1. Yıllara göre vajinal ve sezaryen doğumların dağılımı

\begin{tabular}{cccccccc}
\hline Y11 & $\begin{array}{c}\text { Doğum } \\
\text { sayısı }\end{array}$ & $\begin{array}{c}\text { Vajinal } \\
\text { doğum } \\
\mathrm{n}(\%)\end{array}$ & $\begin{array}{c}\text { Sezaryen } \\
\mathrm{n}(\%)\end{array}$ & $\begin{array}{c}\text { Primer } \\
\text { Sezaryen } \\
\mathrm{n}(\%) *\end{array}$ & $\begin{array}{c}\text { Geçirilmiş uterin } \\
\text { cerrahi } \\
\mathrm{n}(\%) * *\end{array}$ & $\begin{array}{c}<35 \text { yaş } \\
\text { kadınlarda } \\
\mathrm{n}(\%) * * *\end{array}$ & $\begin{array}{c}\geq 35 \text { yaş } \\
\text { kadınlarda } \\
\mathrm{n}(\%) * * *\end{array}$ \\
\hline 2013 & 2687 & $1455(54,2)$ & $1232(45,8)$ & $541(20,1)$ & $723(26,9)$ & $735(59,7)$ & $497(40,3)$ \\
\hline 2014 & 3114 & $1754(56,3)$ & $1360(43,7)$ & $528(16,9)$ & $819(26,3)$ & $845(62,1)$ & $515(37,9)$ \\
\hline 2015 & 3338 & $1824(54,7)$ & $1514(45,3)$ & $599(17,9)$ & $915(27,4)$ & $1007(66,5)$ & $507(33,5)$ \\
\hline 2016 & 3176 & $1724(54,7)$ & $1452(45,7)$ & $653(20,5)$ & $780(24,5)$ & $1128(77,6)$ & $324(22,4)$ \\
\hline Toplam & 12.315 & $6757(54,9)$ & $5558(45,1)$ & $2321(18,8)$ & $3237(26,2)$ & $3715(66,8)$ & $1843(33,2)$ \\
\hline
\end{tabular}

$\mathrm{p} \quad \chi^{2}=3,742 \mathrm{p}=0,291$

*Tüm doğumlar içinde primer sezaryen yüzdesi, ** Tüm doğumlar içinde geçirilmiş uterin cerrahi yüzdesi *** Tüm sezaryen doğumlar içinde yaşa göre sezaryen dağılımı

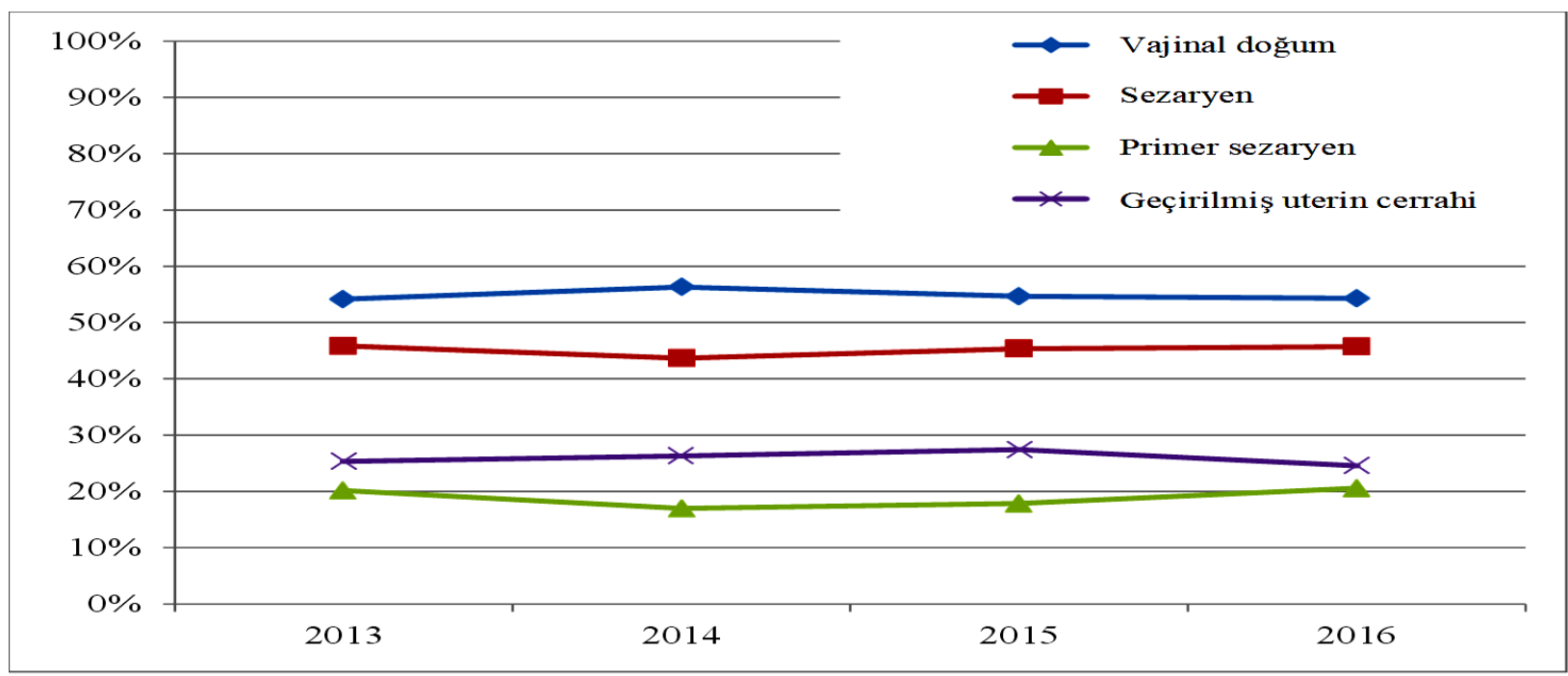

Şekil 1. Y1llara göre sezaryen ve vajinal doğumların dağılımı 
Tablo 2. Yıllara göre sezaryen endikasyonlarının dağılımı

\begin{tabular}{|c|c|c|c|c|c|}
\hline Endikasyonlar & $\begin{array}{c}2013 \\
\mathrm{n}(\%)\end{array}$ & $\begin{array}{c}2014 \\
\text { n (\%) }\end{array}$ & $\begin{array}{c}2015 \\
\text { n }(\%)\end{array}$ & $\begin{array}{r}2016 \\
\mathrm{n}(\%)\end{array}$ & $\begin{array}{r}\text { Toplam } \\
\text { n (\%) }\end{array}$ \\
\hline Geçirilmiş uterin cerrahi & $723(58,6)$ & $819(60,2)$ & $915(60,4)$ & $780(53,7)$ & $3237(58,2)$ \\
\hline Baş pelvis uyumsuzluğu & $160(12,9)$ & $209(15,3)$ & $284(18,7)$ & $288(19,8)$ & $899(16,1)$ \\
\hline Fetal distres & $204(16,5)$ & $143(10,5)$ & $152(10,0)$ & $216(14,8)$ & $715(12,8)$ \\
\hline Makat prezentasyonu & $53(4,3)$ & $47(3,4)$ & $54(3,5)$ & $56(3,8)$ & $210(3,7)$ \\
\hline İribebek & $27(2,1)$ & $35(2,5)$ & $31(2,0)$ & $21(1,4)$ & $114(2,0)$ \\
\hline Çoğul gebelik & $0(1,6)$ & $24(1,7)$ & $28(1,8)$ & $23(1,5)$ & $95(1,7)$ \\
\hline $\begin{array}{l}\text { Diğer prezentasyon anomalileri } \\
\text { (Tranvers, alın, yüz geliş vb.) }\end{array}$ & $0(0,8)$ & $19(1,3)$ & $17(1,1)$ & $21(1,4)$ & $67(1,2)$ \\
\hline $\begin{array}{l}\text { Sistemik hastalıklar** }\left(\mathrm{DM}^{* *}, \mathrm{HT}^{* * *},\right. \\
\text { gebeliğe bağl1 } \mathrm{HT})\end{array}$ & $11(0,8)$ & $30(2,2)$ & $6(0,3)$ & $14(0,9)$ & $61(1,0)$ \\
\hline $\begin{array}{l}\text { Plasenta anomalileri (Plasenta previa, vasa } \\
\text { previa, ablasyo plasenta) }\end{array}$ & $12(0,9$ & $18(1,3)$ & $13(0,8)$ & $17(1,1)$ & $60(1,0)$ \\
\hline Uzamış eylem & $10(0,8)$ & $12(0,8)$ & $14(0,9)$ & $11(0,7)$ & $47(0,8)$ \\
\hline Kordon sarkması & $1(0,08)$ & $3(0,02)$ & 0 & $2(0,1)$ & $6(0,1)$ \\
\hline $\begin{array}{l}\text { Fetal anomaliler (Hidrosefali, } \\
\text { sakrokoksigeal teratom vb.) }\end{array}$ & $1(0,08)$ & $1(0,07)$ & 0 & $3(0,3)$ & $5(0,08)$ \\
\hline Toplam & $1232(45,8)$ & $1360(43,7)$ & $1514(45,3)$ & $1452(45,7)$ & $5558(45,1)$ \\
\hline
\end{tabular}

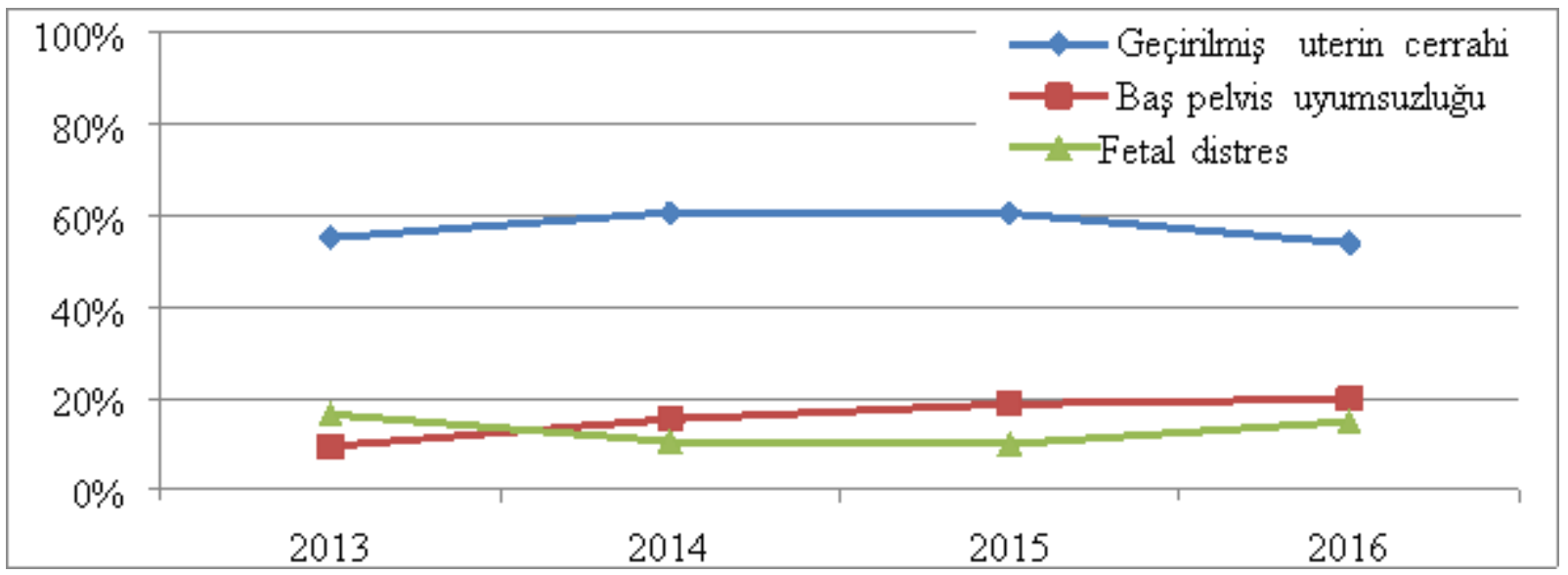

Şekil 2. Yıllara göre en sıı sezaryen endikasyonaları olan geçirilmiş uterin cerrahi, baş pelvis uyumsuzluğu ve Fetal distres dağılımı

Sezaryen doğumların başlıca endikasyonları sırasıyla; geçirilmiş uterin cerrahi (\%58.2), baş pelvis uyumsuzluğu (\%16.1), fetal sıkıntı (\%12.8), makat prezentasyonu (\%3.7), iri bebek (\%2.0), çoğul gebelik (\%1.7), diğer prezentasyon anomalileri (\%1.2), sistemik hastalıklar (\%1.0), plasenta anomalileri (\%1.0), uzamıs eylem (\%0.8), kordon sarkması $(0,1)$, fetal anomaliler $(\% 0,08)$ idi (Tablo 2). 
Toplam dört yıl içindeki en s1k üç sezaryen endikasyonu; geçirilmiş uterin cerrahi (\%58.2), baş pelvis uyumsuzluğu (\%16.1), fetal s1kıntı (\%12.8) olarak saptandı (Şekil 2). Tablo olarak gösterilmemekle birlikte 2013-2016 y1lları arasında gerçekleşen vajinal ve sezaryen doğumlar sonrasinda hastanede morbidite ve mortalite vakası yaşanmadi. Y1llara göre sezaryen ve vajinal doğum oranları arasında istatistiki bir fark bulunmadı $(\mathrm{p}=0.291)($ Tablo 1).

\section{Tartışma}

Sezaryen doğum oranları neredeyse tüm dünya ülkelerinde giderek artmaktadır ve bu oranlar ülkelerin sağlık politikaları ve insanların doğum eylemine bakış açıları ile değişiklik göstermektedir (9). DSÖ tarafından sezaryen hızı olarak önerilen $\% 15$ seviyesinin altına inildiğinde veya üzerine çıkıldı ğında maternal ve perinatal mortalite ve morbiditenin artacağ ve ark. (13) tarafindan yapılan ve 1990-2014 yılları arasını kapsayan küresel, bölgesel ve ulusal verilere ulaşıldığı geniş çaplı bir çalışmada, tüm dünyada sezaryen oran $1 \% 18.6$, Latin Amerika ve Karayip bölgesinde \%40.5, kuzey Amerika da $\% 32.3$, Pasifikte \%31.1, Avrupa da \%25, Asya da $\% 19.2$ ve Afrika da \%7.3 olarak bildirilmektedir. Yani dünyada yaklaşık her beş kadından biri sezaryen ile doğum yapmaktadır. Aynı çalışmada son 24 yıl içinde aralarında Türkiye'nin de olduğu bazı ülkelerde (Misır, Dominik Cumhuriyeti, Gürcistan, Çin gibi) sezaryen doğum sıklıklarında $\% 30$ ‘un üzerinde dikkat çekici artışlar olduğundan bahsedilmektedir (13). Araştırmanın yapıldığ Trabzon ili sağlık müdürlügü 2015 yılı ilk altı aylık verilerine göre; ilin sezaryen oranı \%65.4 olup; bu oran kamu hastanelerinde \%44.4, üniversite hastanesinde \%73.2, özel hastanelerde ise \%73.4'tür (14). Bu çalışmada ise, 2013-2016 yıllar1 ortalama sezaryen oran1 \%45.1, primer sezaryen oranı ise \%18.8'dir. Bu oran, Türkiye'nin sezaryen oranı ortalamas1 olan \%53'ten ve Doğu Karadeniz bölgesi sezaryen oranı olan \%56'dan düşüktür $(6,7)$. Benzer şekilde sezaryen doğum oranlar1 ve endikasyonlarını inceleyen retrospektif çalışmalar incelendiğinde de özellikle üçüncü basamak sağlık kuruluşlarında sezaryen oranının giderek arttığı ve sezaryen hızının \%36-\%75 arasında değiştiği görülmektedir (15-21). Araştırmanın yapıldığı 2013-2016 yılları arasında sezaryen oranlarında genel eğilim olarak artış yönünde olmaması umut verici bir sonuçtur. Ancak yinede bu oranlar hem DSÖ' nün önerdiği orandan (\%15) hem de Sağlık Bakanlığı- TJOD'un (Türk Jinekoloji ve Obstetri Derneği) sezaryen oranlarının azaltılması ortak eylem planında hedeflenen düzey olan \%35'ten belirgin olarak yüksektir (20). Yinede dört yıllık süre zarfında sezaryen oranlarında bir artış olmamasının kamu hastanesi düzeyinde Sağlık Bakanlığı ve TJOD ortak eylem planının ana stratejilerinin (klinik düzeyinde stratejiler, idari stratejiler ve halka yönelik stratejiler) (20) il düzeyinde başarılı bir şekilde uygulandığı şeklinde yorumlanabilir. Bu kapsamda il bazında ebe-hemşirelere yönelik olarak verilen acil obstetrik bakım (AOB) kurslarının, doğum hizmetlerini güçlendirme projesi eğitimlerinin, anne dostu hastane çalışmaları ve bu kapsamda açılan gebe okullarında verilen eğitimlerin sezaryen oranlarının artmamasında etkisi olduğu söylenebilir. Çünkü gerek gebe okullarında gerekse antenatal dönemde verilen doğuma hazırlık eğitimlerinin epidural analjezili vajinal doğum tercihini ve doğuma hazır oluşluğu arttırdığı ve sezaryen doğum oranını azalttığını destekleyen çalışmalar mevcuttur (21). Örneğin Khunpradit ve ark. (22) sezaryen oranlarını azaltmak için klinik dışı müdahaleler başlıklı sistematik derlemelerinde, gebelere verilen doğuma hazırlık eğitimlerinin sezaryen oranlarını düşürdüğü gösterilmiştir. Yine kadın doğum hekimlerinin ve ebelerin, sezaryen ve sezaryen sonrası vajinal doğuma yönelik görüşlerinin incelendiği bir başka çalışmada da, ebe ve hekimlerin çoğunun sezaryen oranlarının azaltılmasında doğuma hazırlık sınıflarının faydalı olacağına inandıkları belirtilmiştir (23).

Literatürde en sik sezaryen endikasyonu geçirilmiş uterin cerrahi olup, bunu pelvik distosi, fetal distres ve prezentasyon anomalileri takip etmektedir (3,9,24-28). Bu çalışmada da literatürle uyumlu olarak en sik sezaryen endikasyonu sırasıyla \%58.2 oranıyla geçirilmiş uterin cerrahi, baş pelvis uyumsuzluğu ve fetal distres takip etmekteydi. Robson'un (8) ABD de yaptığı geniş kapsamlı bir çalışmada sezaryen nedeni olarak en sık dört endikasyon; bir kez geçirilmiş sezaryen (\%41), ilerlemeyen travay (\%13.8), makat geliş (\%6.9), fetal distres (\%6.9) olarak belirtilmiştir. Küçükbaş ve ark. (25) çalışmasında da aynı şekilde en sık üç sezaryen endikasyonu sırasıyla; geçirilmiş sezaryen \%37.8, baş pelvis uyum- 
suzluğu \%16.5 ve fetal distres \%13.8 olarak bildirilmiştir. Yapılan diğer çalışmalar incelendiğinde de benzer şekilde, geçirilmiş sezaryenin endikasyonlar içinde ilk sırada yer aldığ 1 fetal distres, baş pelvis uyumsuzluğu, prezentasyon anomalileri endikasyonlarının ise ikinci, üçüncü ve dördüncü sıralarda değişerek yer aldığ 1 bildirilmiştir (1521,24-28).

Her ne kadar sezaryen doğum annenin ve bebeğin hayatını kurtaran değerli bir girişim olsa da hem anestezi ve cerrahi işleme bağlı riskleri hem de doğum sonu dönemde bazı komplikasyonları beraberinde getirmektedir (3). Oysa kanita dayalı çalışmalar endikasyonun olmadığı durumlarda, sezaryenin anne veya yenidoğana yararı olmadığını göstermektedir. Bu çalışmalarda, doğum şeklinin sadece beş sonucu etkilediği gösterilmektedir. Bunlar: 1) Maternal kanama, 2) Annenin hastanede yatış süresi, 3) Yenidoğan respiratuar morbiditesi, 4) Takip eden gebeliklerde plasenta previa/akreta, 5) Uterus rüptürüdür. Sonuçlardan sadece maternal kanama planlı sezaryen doğum lehineyken diğer dördünde vajinal doğum avantajlıdır (3). $\mathrm{Bu}$ nedenle, normal doğum öyküsü olan düşük riskli primigravida veya multipar kadınlarda sezaryen kararı verirken, sezaryen endikasyonlarının tekrar gözden geçirilmesi sezaryen oranlarının düşürülmesinde etkili olabileceğinden bahsedilmektedir (25). Yine düşük riskli gebelerde sezaryen sonrası vajinal doğum, tüm risk ve avantajları ile değerlendirilir ve desteklenirse geçirilmiş sezaryen sebebiyle yapılan sezaryen oranının düşürülmesine katk1 verebilir $(2,12,29)$. Nitekim Costa ve ark. (24) tarafindan Portekiz de yapılan bir çalışmada, 2005 ile 2011 sezaryen oranlarındaki düşüşü primer sezaryen doğumlarındaki; external fetal versiyon programının uygulanması, düşük riskli gebeliklerde sadece 41. gebelik haftasından sonra indüksiyon yapılması ve düşük riskli maternal-fetal hastalık durumlarında vajinal doğum denemesi gibi uygulamalardan kaynaklandığı belirtilmiştir.

$\mathrm{Bu}$ çalışmada, önceden geçirilmiş sezaryen olmayan kadınlarda en sik ikinci sezaryen endikasyonu baş pelvis uyumsuzluğudur. Benzer şekilde hem ülkemizde hem de yurt dışında yapılan çalışmalarda baş pelvis uyumsuzluğu primer sezaryen için majör endikasyonlardan biri olarak gösterilmektedir $(3,9,10,15-19,21,24)$. Amerikan Obstetrik ve Jinekoloji Derneği (ACOG) ve Ulusal Çocuk Sağlığı Ve İnsan Gelişimi Enstitüsü (National Institute of Child Health and Human
Development -NICHD) tarafindan 2016'da yenilenen çalıştay sonuçlarına göre, hekimlerin baş pelvis uyumsuzluğu tanısı koyarken yeterince beklememelerine bağlı sezaryen oranlarında artış olduğu öne sürülmektedir (12). Bu veriyi destekler şekilde 2015 yılında yayımlanan "Doğumun ilk aşamasının yönetimi: Sezaryen doğum oranını düşürmek için potansiyel stratejiler" başlıklı sistematik derlemede, doğum müdahalelerinin çoğunun gerçekleştiği birinci evrede çoğu hekim ve ebenin distosinin tanılanması için "daha fazla zamana" ihtiyaç duydukları belirtilmektedir (30). Benzer şekilde ACOG ve Maternal-Fetal Tip Derneği'nin 2016 yılında doğumun birinci ve ikinci evresindeki bekleme süreleri ve uygulama önerilerini kanıt düzeyleriyle belirterek güncelledikleri "primer sezaryen doğumun güvenli önlenmesi" ortak görüş bildirisinde; doğum distozisi tanımının yeniden gözden geçirilmesinin gerektiğini çünkü mevcut güncel verilerin doğum eyleminin tarihsel olarak öğretilenden daha yavaş ilerlediğini gösterdiğine vurgu yapılmaktadır (12). Bu önerileden yola çıkarak anne ve bebeğin iyilik hali göz önünde bulundurularak, distosinin tanılanmas1 ve doğru müdahalelerin doğru zamanda yapılması, gereken sürenin tanınması hakkında ebe ve hekimlerin bilgilendirilmesi ile sezaryen oranları düşürülebilir (25).

Son y1llarda antenatal tanı yöntemlerinin yaygın kullanımıyla birlikte fetal distresin önceden belirlenmesi sezaryen oranını arttıran önemli bir neden olarak görülmektedir. Çünkü yanlış pozitiflik sebebiyle fetal distres tanısı alan fakat gerçekten stres altında olmayan fetüslerin sezaryenle doğurtulması sezaryen oranlarını arttırdığı düşünülmektedir (31-32). Yapılan çalışmalarda, fetal distres genelde en sik ikinci veya üçüncü sırada sezaryen endikasyonu olarak belirtilmektedir $(3,10,17,25)$. Benzer şekilde bu çalışmada da fetal distres en s1k üçüncü sezaryen endikasyonu olarak saptandi. $\mathrm{Bu}$ çalışmanın yapıldığ hastanede travaydaki gebeler elektronik fetal monitorizasyon (EFM) ile izlenmektedir. Bununla birlikte sürekli EFM ile aralıklı oskültasyon uygulamasının karşılaştırıldığı Cochrane sistematik derlemesinde, sürekli EFM ile izlenen gebelerin sezaryen oranlarının aralıklı oskültasyonla izlenen gebelere göre anlamlı olarak daha fazla olduğu bildirilmiştir (32). Yine ACOG ve NICHD 2016 yılında güncelleyerek yayınladıkları "primer sezaryen doğumun güvenli önlenmesi" 
ortak görüş bildirisinde; EFM'nin yorumlanmasında ve yönetiminde standartlaştırılmış bir terminoloji oluşturulmasının primer sezaryen oranlarının azaltılmasında etkili olabileceği belirtilmektedir (12). Bu doğrultuda sürekli EFM'nin neden olduğu sezaryen oranlarını azaltmak için rehberleri basitleştirerek güncellemek ve sezaryen uygulamak için gerekli eşiği yükselterek yanlış pozitif değerlendirme oranlarını azaltmak uygun olabilir.

Makat geliş, fetal başın takılması ve kordon prolapsusu sebebiyle sezaryen endikasyonlarında sik görülen bir diğer sebeptir $(19,28)$. Ancak iri fetüs, uygunsuz pelvis, ayak geliş ve başın hiperekstansiyonu gibi ek bir sezaryen endikasyonu olmadiğ 1 durumlarda makat geliş hastalarında vajinal doğum denenebilir (33). Planlı vajinal makat doğumda perinatal mortalite ve morbidite risklerini inceleyen bir metaanalize göre; makat prezentasyonlu gebeliklerin vajinal yolla doğurtulmasının sezaryene göre riskli olduğu fakat bu riskin çok yüksek olmadığı ve gebeye özel, bireysel doğum yöntemi kararı verilebileceği belirtilmektedir (33). Bununla birlikte ACOG, makat prezentasyonu ile izlenen gebelere bilgilendirme yapılmas1 durumunda sezaryenin önerilmesini desteklemektedir (34). Ülkemizde yapılan çalışmalarda makat prezantasyonunun \%2,9-\%10 oranları arasında değişerek dördüncü ve/veya beşinci sırada en sık sezaryen endikasyonuna neden olduğu bildirilmektedir $(3,9,21,28,29)$. Bu çalışmada ise makat geliş dördüncü en sık sezaryen endikasyonu olarak saptandi.

Makrozomi 4000 gramın veya 90 persantilin üzerindeki bebekler için kullanılan bir terimdir $(34,35)$ ve yapılan çalışmalarda sezaryen oranlarında artışa neden olduğu gösterilmiştir $(3,18,19,24-28)$. Bu çalışmada ise iri fetüs beşinci en sik sezaryen nedeni olarak tespit edildi. Çalışmanın yapıldığg hastanede, $4000 \mathrm{~g}$ ve üzeri tahmini fetal ağırlı belirlenen fetüsler makrozomik fetüs olarak değerlendirilmekte ve olası vajinal doğum komplikasyonlarının (omuz distozisi, fetal morbidite vb.) önlenmesi için sezaryen doğum önerilmektedir. Ancak günümüzde, fetal boyuttaki aşırılığın tam bir ölçümünün mümkün olmadığı belirtilmektedir. $\mathrm{Bu}$ veriyi destekler şekilde Rouse ve ark. (36) yaptığı bir çalışmada ultrason fetal boyutun tahmininde \%60 sensitiv ve $\% 90$ spesifik olarak bulunmuştur. Yani iri fetüs tanıs ile sezaryen yapılan gebelerin $\% 40$ ' 1 iri değildir. ACOG ise, diyabetik anne fetüslerinde $4500 \mathrm{~g}$, diğer anne fetüslerinde ise $5000 \mathrm{~g}$ ve üzerinde makrozomik fetüs tanısı konulması durumunda sezaryen planlanmasını önermektedir (34).

$\mathrm{Bu}$ çalışmada diğer sezaryen endikasyonları olan çoğul gebelik, maternal sistemik hastalıklar, diğer prezentasyon anomalileri, uzamış eylem, plasenta anomalileri, fetal anomaliler ve kordon sarkması \%'2'nin altında bir sıklık gösterdikleri için literatür eşliğinde tartışılmamıştır.

Literatürde kadının yaşı arttıkça sezaryen doğum oranlarının da arttığı belirtilmektedir (10,26,37-38). Fakat bu çalışmada, 35 yaştan küçük olan kadınlarda sezaryen oranının, $\geq 35$ yaş olan kadınlara göre daha yüksek olduğu saptandi. Çalışmamız, ileri yaş ile sezaryen doğum riskinin artması arasında ilişki olduğunu bildiren mevcut literatürle uyumlu değildir. Bunun nedeni olarakta, her ne kadar araştırmalarda sezaryen endikasyonları arasında geçmese de ilk doğumunu yapacak olan kadınların isteğe bağlı sezaryen tercihlerinin önemli bir katkısı olabileceği düşünülmektedir. Günümüzde kadınların bilinçli olarak en başından sezaryen doğum istemesi ve gebelik süresince de buna uygun adımlar atması sezaryen oranlarının artmasında önemli bir yer tutmaktadır $(9,38,39)$. $\mathrm{Bu}$ durum göz önüne alındığında ülkemizde de giderek artan sezaryen oranlarını anlamak ve bu konuda başarılı müdahaleler oluşturabilmek için kadınların doğum şekli tercihlerine etki eden faktörleri bilmek önem kazanmaktadır. Kadınların doğum tercihlerinin incelendiği araştırmalar göstermektedir ki sezaryenle doğum yapmak isteyen kadınların; en fazla doğum ve doğum ağrısından korktukları için, kıymetli bebek/tedavi ile hamile kaldıkları için, tüplerini bağlatmak istedikler için, anne ve bebek için daha sağlıklı olduğunu ve daha kolay olduğunu düşündükleri için, vajinal doğumdaki pozisyon ve muayenelerden rahatsız oldukları için, doğum yapacağı tarihi önceden bilmek istedikleri için, önceki doğumu zor ya da sezaryen olduğu için, gebeliği sürecinde aile ve arkadaş etkisinde kaldığ 1 için ve hekim isteği gibi nedenlerden dolayı sezaryen doğumu tercih ettikleri belirtilmektedir $(3,9,47,48)$. Bu nedenle kadınların doğumdan beklentilerini ortaya çıkarmak ve bu süreçte ihtiyaçları olan bilgi, destek ve bakımı verebilmek açısından doğum şekli ile ilgili tercihlerini belirlemek ve karar sürecine katılmalarını sağlamak önemlidir (9). Bu bilgiler 
doğrultusunda, gebelerin vajinal doğum ve sezaryenin avantajları ve dezavantajları konusunda bilgilendirilmeleri ve vajinal doğum açısından cesaretlendirilmeleri anne isteğine bağlı sezaryen oranını azaltmada etkili olabileceği söylenebilir.

\section{Sonuç ve Öneriler}

Çalışma sonucunda sezaryen oranı Türkiye ortalamasın altında fakat DSÖ'nün belirlediği orandan oldukça yüksektir. Ancak çalışmanın yapıldığ1 hastane üçüncü basamak referans bir hastane olmasına rağmen, yıllara göre sezaryen ile doğum oranlarında anlamlı bir artış izlenmedi. Çalışmada tüm yıllar için en sık sezaryen endikasyonu geçirilmiş uterin cerrahi idi.

Sonuç olarak, yıllar içinde giderek yükselen sezaryen doğum oranlarının doğru atılacak stratejik adımlarla ve multidisipliner çalışmalarla zaman içinde azaltılabileceği düşünülmektedir. $\mathrm{Bu}$ bağlamda kanıta dayalı uygulamaları klinik ile birleștirmek son derece önem kazanmaktadır (40). Bunun için de ana hedef "daha az sezaryen" değil, "daha doğru travay ve doğum yönetimi" olmalıdır (20). Bu sebeple, ilerlemeyen eylem, fetal distres, baş-pelvis uyumsuzluğu gibi endikasyonların daha objektif kriterlere oturtulmas1, tanı kriterlerinin güncellenmesi, travay ve doğum süresince yapılan müdahale ve muayene sonuçlarının partograf ile izlenmesi, doğum eyleminin takibinde aralıklı monitörizasyon yapılmas1, anormal kardiotokografi durumunda sezaryen öncesi fetal kan örneklemesi yapılmas1, makat prezentasyonlarda uygun vakalarda vajinal doğum denenmesi, eksternal sefalik versiyon gibi operatif vajinal doğum oranının arttırılması, sezaryen oranlarının analizinde Robson's Kriterlerinin kullanılması, obstetrik analjezi ve anestezinin yaygınlaştırılması, hekimlerin üzerindeki medigolegal baskının azaltılması ve malpraktis yasasının gözden geçirilmesi gibi önlemler uygulamaya konularak kadın doğum hekimleri için standart bir yol gösterici rehber oluşturulması primer sezaryen oranlarını azaltabilir. Bununla birlikte sezaryen oranlarını düşürülmesinde özellikle ebelerin işbirliğinin önemi anlaşılmalıdır. Bu doğrultuda kanita dayalı uygulamaların klinik ile birleştirilmesi için ebelerin doğumda daha aktif rol almasının sağlanması, kanıta dayalı uygulamaları içeren hizmet içi eğitim programlarının arttırılması, ebelerin güncel gelişmeleri takip etmeleri ve ebeler tarafindan kadınlara yönelik doğuma hazırlık kurslarının yaygınlaştırılması ve doğuma yönelik olumlu tutum geliştirilmesi desteklenmelidir. Ayrıca anne adaylarının vajinal doğum ve sezaryenin avantajları ve dezavantajları konusunda bilgilendirilmeleri ve vajinal doğum açısından cesaretlendirilmeleri de anne isteğine bağlı sezaryen oranını azaltmada büyük rol oynayacaktır.

\section{Kaynaklar}

1. Souza JP, Betran AP, Dumont A, De Mucio B, GibbsPickens CM, Deneux-tharaux C, et al. A global reference for caesarean section rates $(\mathrm{C}$ Model): a multi country cross-section al study. BJOG 2016;123(3):427-36.

2. T.C. Sağlık Bakanlığı Ana Çocuk Sağlığı ve Aile Planlaması Genel Müdürlügü. Doğum ve Sezaryen Eylemi Yönetim Rehberi. Ankara: Damla Matbaacilik; 2010.

3. Sayın NC, Erzincan SG, Çilingir IU. Sezaryen: kanita dayalı bilgiler. Turkiye Klinikleri J Gynecol Obst-Special Topics 2018; 11(1), 7681.

4. Mathai M, Hofmeyr GJ, Mathai NE. Abdominal surgical incisions for caesarean section. Cochrane Database Syst Rev 2013; (5): CD004453.

5. World Health Organization, WHO Statement on Caeserean Rates 2015. (Erișim Tarihi: 16/03/2018) Erişim adresi: http://www.who. int/reproductivehealth/publications/maternal_ perinatal_health/cs-statement/.

6. Hacettepe Üniversitesi Nüfus Etütleri Enstitüsü 2014." 2013 Türkiye Nüfus ve Sağllk Araştırması" Hacettepe Üniversitesi Nüfus Etütleri Enstitüsü, T.C. Kalkınma Bakanlığı ve TÜBİTAK, Ankara, Türkiye, ss.150.

7. T.C.Sağlık Bakanlığ 1 Sağlık İstatistikleri Y1llığ 2015. (Erişim Tarihi: 16/03/2018) Erişim adresi:

www.sagem.gov.tr/dosyalar/SIY_2015.pdf.

8. Robson SJ, de Costa CM. Thirty years of the World Health Organization's target caesarean section rate: time to move on. Med J Aust 2017;206(4):181-5.

9. Karabel MP, Demirbaş M, İnci MB. Türkiye'de ve dünya'da değişen sezaryen sıklığ 1 ve olası nedenleri. Sakarya Med J. 2017; 7(4):158-163.

10.Begum T, Rahman A, Nababan H, Hoque DME, Khan AF, Ali T, Anwar I. Indications and determinants of caesarean section delivery: 
Evidence from a population-based study in Matlab, Bangladesh. PLoS One 2017; 12(11): e0188074.

11.American College of Obstetricians and Gynecologists (ACOG) Committee opinion no. 559: Cesarean delivery on maternal request. Obstet Gynecol 2013; 121(4):904-7.

12.American College of Obstetricians and Gynecologists (ACOG); Society for MaternalFetal Medicine. Obstetric care consensus no. 1: safe prevention of the primary cesarean delivery. Obstet Gynecol 2014;123:693-711.

13.Betran AP, Ye J, Moller A, Zhang J, Gulmezoglu AM, Torloni MR. The Increasing Trend in Caesarean Section Rates: Global, Regionaland National Estimates: 1990-2014. PLoS One 2016; 11(2): e148343.

14.Trabzon İl Sağlık Müdürlüğü İstatistikleri 2017. (Erişim tarihi: 18.03.2018).Erişim adresi: trbism.gov.tr/

15.Aksoy H, Özyurt S, Aksoy Ü, Açmaz G, Karadağ Öİ, Babayiğit MA. Hastanemizdeki sezaryen hızı ve endikasyon dağılımları ışığında Türkiye' de sezaryen ile doğuma genel bakış. Kocaeli Med J.2014; 3, 1-7.

16.Uzunçakmak C, Gülda A, Aydın S, Var A, Özçam H. S.B. İstanbul Eğitim Araştırma Hastanesi Kadın Hastalıkları ve Doğum Kliniği'nde 2005-2012 yılları arasında sezaryen ile doğum yapan hastaların değerlendirilmesi. İstanbul Med J. 2013; 14: 112-6.

17. Yıldız A, Köksal A, Çukurova K, Keklik A, Çelik N, İvit H. Bir obsetetrik kliniğinde 15 y1llı period süresince sezaryen oranları ve endikasyonlarının yıllara göre dağılımı. Nobel Med. 2010; 6, 10-14.

18.Mutlu İ, Mutlu MF, Demir A, Efetürk T, Kiseli M. Kliniğimiz 2009-2012 yılları arasında saptanan sezaryen oranlari: sezaryen oranlarındaki artış kaçınılmaz mı? Gazi Med J. 2013; 24:40-3.

19.İ̧̧ü̈der ÇK, Bulut YE, Yılmaz G, Doğru HY, Özsoy AZ, Başol N. Kliniğimizde 2014-2016 yıllar1 arasinda sezaryen oran1 ve endikasyonları. Jinekol Obstet Neonatol Tip Derg 2017; 14(4).

20.Türk Jinekoloji ve Obstetrik Derneği (TJOD): Sağlık Bakanlığı - TJOD sezaryen oranlarını azaltma ortak eylem planı 2013. (Erişim tarihi: 10/02/2018) Erişim adresi: http://www.tjod. org/saglik-bakanligi-tjodsezaryen-oranlariniazaltma-ortak-eylem plani/.

21.Mete S, Çiçek Ö, Aluş TM, Çamlıbel M, Uludağ E. Doğuma hazırlık sınıflarının doğum korkusu, doğum tercihi ve doğuma hazır oluşluğa etkisi. Turkiye Klinikleri J Nurs Sci. 2017; 9(3), 201206.

22. Khunpradit S, Tavender E, Lumbiganon $\mathrm{P}$, Laopaiboon M, Wasiak J, Gruen RL. Nonclinical interventions for reducing unnecessary caesarean section. Cochrane Database Syst Rev 2011; (6):CD005528.

23. Kisa S, Kisa A, Younis MZ. Opinions and attitudes of obstetricians and midwives in Turkey towards caesarean section and vajinal birth following a previous caesarean section. J Int Med Res. 2017 Dec; 45(6): 1739-1749.

24. Costa A, Policiano C, Clode N, Graça LM. Indications for caeserean deliveries during a 7year period in a tertiary hospital. Acta Med Port 2013; 26:649-54.

25.Küçükbaş NG, Moraloğlu Ö, Özel Ş, Erkaya S, Taşçı Y, Fındık RB. Dr. Zekai Tahir Burak Kadın Sağlığ 1 Eğitim ve Araştırma Hastanesi Doğum Ünitesi'nde 2010-2014 sezaryen oranları ve endikasyonları. Perinatol Derg 2016; 24(2):61-65 DOI: 10.2399 /prn.16.0242001.

26.Inal ZO, Inal HA, Küçükkendirci H, Oruç AS. Investigation of cesarean sections at Konya Training and Research Hospital Obstetrics and Gynecology Department between 2010 and 2015. Ginekologia polska 2017; 88(4),185-190.

27.Çağlayan EK, Kara M, Gürel Y. Kliniğimizde üç yıllık sezaryen oranı ve endikasyonları. Journal of Experimental and Clinical Med 2011; 27(2), 50-53.

28. Yılmaz M, İsaoğlu Ü, Kadanalı S. Kliniğimizde 2002-2007 y1llar1 arasinda sezaryen olan hastaların incelenmesi. Marmara Med J 2009; 22: 104-10.

29.Nousia K, Michalopoulos G, Grigoriadis C, Stournaras S, Brezeanou C, Vrachnis N, Farmakides G. Vajinal birth after cesarean section in Greece and the contribution of the midwives. HJOG 2014; 13(3):73-76.

30.Jackson S, Gregory KD. Management of the First Stage of Labor: Potential Strategies to Lower the Cesarean Delivery Rate. Clin Obstet Gynecol 2015; 58(2):217-226. 
31. Costantine MM, Saade GR. The first cesarean: role of "fetal distress" diagnosis. Semin Perinatol 2012; 36: 379-83.

32. Alfirevic Z, Devane D, Gyte GM. Continuous cardiotocography (CTG) as a form of electronic fetal monitoring (EFM) for fetal assessment during labour. Cochrane Database Syst Rev 2013; (5): CD006066. doi: 10.1002/14651858. CD006066.pub2.

33.Berhan Y, Haileamlak A. The risks of planned vajinal breech delivery versus planned caesarean section for term breech birth: a metaanalysis including observational studies. BJOG 2016; 123:49-57.

34.American College of Obstetricians and Gynecologists (ACOG) Committee on Obstetric Practice. ACOG Committee Opinion No. 340. Mode of term singleton breech delivery. Obstet Gynecol 2006; 108:235-7.

35. Rouse DJ, Owen J, Goldenberg RL, Cliver SP. The effectiveness and cost of elective cesarean delivery for fetal macrosomia diagnosed by ultrasound. JAMA 1996; 276: 1480-1486.

36.Avşar F, Taş E. Makrozomik fetüs ve takibi. Türkiye Klinikleri J Gynecol Obst-Special Topics 2011; 4: 257-63.

37.Luck M, Savitsky L, Speranza R,Caughey A. The Rate of Cesarean Section Stratified by Maternal Age, Parity and Previous History of Cesarean Section [13Q]. Obstetrics \& Gynecology 2017; 129, 176 S.

38.Büyükbayrak EE, Kaymaz O, Kars B, Karsidag AY, Bektas E, Unal O, Turan C. Caesarean delivery or vajinal birth: preference of Turkish pregnant women and influencing factors. Journal of Obstetrics \& Gynaecology. 2010; 30(2):155-158.

39. Vatansever Z, Okumuş H. Gebelerin doğum şekline karar verme durumlarının incelenmesi. DEUHYO ED 2013; 6 (2), 82-87.

40.Vural G, Erenel AŞ. Doğumun medikalizasyonu neden artmıştır, azalta bilir miyiz?. Hacettepe Univ Hemşirelik Fak Derg 2017;4(2). 